\title{
Rights, Wronging, and the Snares of Non-Identity
}

\author{
RAHUL KUMAR \\ Queen's University
}

\begin{abstract}
Chapter five of Boonin's The Non-Identity Problem and the Ethics of Future People examines what he identifies as the fourth premise of the nonidentity argument: if an act harms no one it wrongs no one. He argues that the reasons for rejecting it offer no grounds for resisting the conclusion of the non-identity problem. I argue that key arguments for this claim subtly misconstrue non-consequentialist reasoning about wronging. This shows, I suggest, that the prospects for resisting the non-identity problem by harnessing the resources of a general account of what it is for one person to wrong another are in fact quite bright.
\end{abstract}

Keywords: Rights, non-consequentialism, deontology, non-identity, wronging.

\section{INTRODUCTION}

The non-identity problem starts with the observation that what a person chooses now can determine the metaphysical identity of those who will exist in the future. Seemingly innocuous, it yields, together with a few independently plausible premises, a startling conclusion, one nicely illustrated by the case of Wilma, who has to decide when to conceive. ${ }^{1}$ If she conceives now, she will give birth to a blind child, Pebbles. But if she postpones conception and accepts the minor inconvenience of taking a pill each day for the next two months before proceeding, she will give birth to a sighted child, Rocks.

Intuitively, Wilma deciding to conceive now rather than waiting two

months is wrong. It is wrong because, in choosing not to spare her child a significant disadvantage in life, when she can easily do so, she wrongs it.

1 This is the central example Boonin works throughout his book. 
What the non-identity problem draws our attention to is the significance of blind Pebbles being the product of the union of a different sperm and egg than that which yields sighted Rocks. What turns on Wilma's decision, therefore, is not the fate of a particular person who will either be born better or worse off, depending on what she decides, but which of two distinct individuals will be brought into existence-blind Pebbles or sighted Rocks.

Neither Pebbles nor Rocks is rendered better or worse off by being conceived than she or he would have been had Wilma decided differently. But if Wilma deciding to conceive now rather than wait will not make the resulting child, Pebbles, worse off than she otherwise would have been, it is hard to see how she is harmed by Wilma's choice. And if Pebbles is not harmed, what basis do we have for the intuitive conviction that it would be wrong for Wilma not to wait because not waiting would wrong her future child? The unintuitive conclusion, that Wilma deciding to conceive now is not wrong because doing so would not harm her child, ends up looking difficult to resist.

One of the many delights and challenges of The Non-Identity Problem and the Ethics of Future People is the care with which David Boonin interrogates an array of arguments that aim to show one of the premises of the argument for the unintuitive conclusion to be mistaken. Finding them all unsatisfactory, he concludes that the only philosophically defensible option is to simply embrace it as true: the non-identity problem should be viewed not as a problem to be overcome, but as an argument establishing an important moral truth.

I remain unconvinced. The challenges to the non-identity problem Boonin surveys may not, as stated, succeed. But they can be improved upon, rendering them more effective against the premises of the argument they target. In particular, I think it is worth looking more closely at what Boonin identifies as P4 of the non-identity argument, which holds that if an act does not harm anyone, then the act does not wrong anyone. What he asks is whether there is a way of understanding an act as wronging another, even if it could not, in principle, harm her, that can be employed to dissolve the non-identity problem. His conclusion is that there is not (Boonin, 2014:148). Certain arguments for why this is so, however, seem to me to subtly misconstrue non-consequentialist reasoning about wronging, and in ways that close off the possibility that a better general understanding of what it is for one person to wrong another might give us good grounds for resisting P4 (and hence the Implausible Conclusion).

To develop this claim, I want to first consider Boonin's arguments as to why appealing to the rights of those who will be brought into existence 
cannot help dissolve the non-identity problem. I will then turn to his critical discussion of what he calls the 'actual and de dicto' approach. Both strands of argument capture insights, I will argue, that can be put to work as part of a defense of the rejection of the fourth premise as crucial to dissolving the non-identity problem.

\section{BOONIN ON RIGHTS-BASED SOLUTIONS}

Many are drawn to the thought that a choice resulting in a person coming into existence can still wrong her-even if she would not have otherwise come into existence and has a life worth living-because the making of that choice violated her rights. Boonin helpfully distinguishes between direct and indirect versions of this argumentative strategy. The direct version says that Wilma choosing to conceive now rather than later wrongs Pebbles because that choice violates a right that Pebbles has at the time the choice is to be made. The indirect version says that Wilma's act of choosing to conceive Pebbles generates a new right in Pebbles that will foreseeably be violated.

The direct version requires that we posit the objection to Wilma conceiving Pebbles as Pebbles' claim-right against Wilma that she not do so. That there is such a right looks difficult to make sense of, let alone defend. How can a person who was not previously in existence and does not now exist be the bearer of a right that requires that the very choice that will bring her into existence not be made? The indirect version of the rights-based strategy looks comparatively more promising. Assuming that each person has a right not to exist as blind, and Pebbles can only exist as blind, conceiving Pebbles is to choose to bring someone into existence whose right cannot be honoured. More precisely, the proposal is that her only being able to exist as wronged, because her right cannot be honoured, is a decisive reason for Wilma to delay conceiving.

Boonin argues that indirectly appealing to Pebbles' right cannot preserve the intuitive conviction that Wilma ought not to conceive now because doing so would wrong Pebbles. Two arguments for this conclusion are, for my purposes, of particular importance. First, if Pebbles has a right not to be born blind, it follows that Wilma violates that right by bringing her into existence, whether or not Wilma is able to conceive a sighted child. That is implausible. Wilma arguably owes it to any child she chooses to conceive to take reasonable steps to ensure that the child is born without any significant impairments. But if, for reasons outside her control, she can only conceive children who will be born blind but have otherwise good lives, she does not, even defeasibly, wrong anyone when she decides to 
conceive. The suggestion that she does is even less plausible than that of Wilma doing no wrong in bringing Pebbles rather than Rocks into existence.

The second argument is one not explicitly stated, but is one I take to underlie both Boonin's discussions of permissible rights-infringements and the 'rights waiver' argument (Boonin, 2014:116, 119-23). It goes as follows: if Pebbles has a right not to be born blind, it is reasonable to think that there must be some value for Pebbles in having the kind of protection the right in question affords her. But it is doubtful that the right does in fact have any value for her, which is a reason to think the right in question lacks a rationale, other than the positing of it appearing to offer grounds for resisting the non-identity problem.

Consider, first, Boonin's discussion of a rights-infringement case:

“Suppose, for example, that you will soon die if I don't donate a kidney to you, and that I can either promise that I will give you a kidney and promise that I will paint your house, in which case I will keep the first promise but break the second promise, or that I can promise to do neither, in which case I will do neither. In this case, it seems clear that it would not be wrong for me to make both promises and then keep the first one, even though doing so would again generate in you a right that would later be violated. This suggests that even if the generation of a new right that will later be violated establishes a moral presumption against doing an act, the presumption can be overcome if there is a substantial enough difference in terms of the overall consequences between doing the act and not doing the act. Even if Wilma's act of conceiving Pebbles does prove to generate a new right in Pebbles that will later be violated, then, this will not be enough to show that her act was immoral....If it is not wrong to generate a right that will later be violated when doing so is necessary in order to save someone's life, then why should it be wrong to generate a right that will later be violated when doing so is necessary in order to give someone a life that would be worth saving in the first place?" (Boonin, 2014:116).

Proponents of a rights-based approach to morality will point out that the kind of 'overcoming' that this passage suggests is meant to be excluded by taking the reason the right provides seriously. As they see it, allowing the reason to respect a justified right to be overcome by substantially better overall consequences of violating it simply undermines the value of having the protection the right affords. But Boonin's point, I take it, is not that the presumption that the right be honored is simply 'overcome'. Rather, it is that specifying the contours of the right by reference to the interests of the 
individual that the right is meant to protect shows that, in the promising case, there is no reason to hold that not keeping the promise to paint the house violates the individual's right, and that in Pebbles' case, there is no reason to think that her right is violated if she is born blind. ${ }^{2}$ In general, if having the protection a right affords is not in the right-holder's interest, why posit such a right to begin with?

This point is even more crisply illustrated by the 'rights-waiver' argument, which goes as follows:

"if Pebbles really does have a right not to be brought into existence as a blind person, for example, it is reasonable to suppose hypothetically that she would agree to waive her right against Wilma conceiving her if she could or to conclude that she actually will agree to waive her right after the fact if Wilma conceives her...blindness is presumably a bad condition to exist in, but it is not so bad that it is worse than not existing at all and so, on the whole....Pebbles will be glad that she was conceived despite her lack of vision. And if Pebbles would or will waive her right not to be conceived under the circumstances in which Wilma conceives her, then the fact that she has a right not to be conceived under those circumstances - if it is a fact—cannot make it morally wrong for Wilma to conceive her" (Boonin, 2014:120).

It is, I agree, plausible that Pebbles would waive any right she has not to be conceived because she will be blind. This is because the protection the right provides is not a right that protects her interests. Quite the opposite, it is an obstacle to her existing as a subject with interests and a life worth living. This fact is epistemically accessible to Wilma prior to conception. She is in a position to know that refusing to violate Pebbles' right not to be born blind cannot be justified on the grounds that she is respecting Pebbles' interests or status. From her point of view, allowing the right in question to play a role in her deliberations looks like a form of rights fetishism. But if the right in question does not provide Pebbles a form of protection she has reason to value, and there is no reason for Wilma to give it any role in her deliberations, why think that there is any such right to begin with? ${ }^{3}$

Advocates of rights-based solution to the non-identity problem ought, I believe, to agree: there is no such right. That is, Pebbles has no right to be

2 For useful discussion, see Oberdiek (2004).

3 I assume here that the wider society has no interests that might be compromised by people choosing to conceive children who will be born blind. 
born sighted, such that she is wronged if she is born blind. What they should go on to say, however, is that it is not their view that a right-in particular, a claim-right correlated with another's duty-is properly understood as an entitlement to a certain state of affairs obtaining, such that one is wronged by that state failing to obtain. Individual rights are fundamentally relational in character: each marks out a respect in which an individual is entitled to have certain of her vital interests be recognized by others, by way of giving their protection priority over other considerations in the practical deliberations of the person against whom the right is held. Taken together, individual rights form a 'moral basic structure': a web of duties and permissions that govern how individuals are to relate to one another in a range of circumstances.

The interest individuals generally have in not having a certain type of state of affairs obtain partially fills out the content of a given individual right. But my right that you not make a certain choice is one that I have in virtue of the fact you stand in a position relative to me of someone whose choices can affect the interests of someone in my position, in ways that persons in my position generally have good reason to want to be protected against. The right provides this protection by requiring that one against whom I have a claim, in virtue of my right, conduct herself in a way that is consistent with prioritizing in her practical deliberations the securing of my interests.

For instance, if I promise to take you to your doctor's appointment, you have a claim-right against me that I do so. What that entitles you to is that in planning my day, I organize it in a way that is compatible with getting you to the appointment on time-even if doing so is not optimal from the point of view of my own interests-and that I make a reasonable effort to stick to the plan. This last qualification is important for understanding what counts as a violation of a right. I may not succeed in getting you to your appointment on time. Whether or not my failure counts as a violation of your right depends, however, on the circumstances which account for the failure. I wrong you if I'm late because I didn't bother taking into account the traffic around the hour of your appointment. But I don't wrong you if I'm late because someone ran a red light and slammed into my car. To violate your right, such that resentment and a demand for compensation are justified, it isn't enough that the right outcome fails to obtain. The failure has to be traceable to my failure to be guided by your interests in the way to which you are entitled by your right.

Now consider a different case, one in which I cut through your backyard as a shortcut on my walk to the coffee shop, reasonably assuming you will not mind. In so doing, I violate your property right. The interest the 
property right protects is your interest in it being up to you to decide who gets to use your property. I may be right that you would not object to my cutting through your backyard, but the point of the property right is to deny others the authority to make a call concerning the use of your property. My taking the shortcut wrongs you.

That would not, of course, be true if I cut through your backyard to save your life, my own life, or someone else's life (cf. Boonin, 2014: 122). Rights are not absolute; they have contours that reflect a balance between the interests of the right holder in having a certain kind of protection and ways in which respecting an individual's right can be burdensome or costly for others.

This way of understanding rights claims is what I believe advocates of rights-based response to the non-identity problem have in mind. Consider, for example, Woodward's influential discussion of the non-identity problem as it arises in the context of Parfit's Risky Policy case. That case goes as follows:

The Risky Policy as a community, we must choose between two energy policies. Both would be completely safe for at least three centuries, but one would have certain risks in the further future. This policy involves the burial of nuclear waste in areas where, in the next few centuries, there is no risk of an earthquake. But since this waste will remain radio-active for thousands of years, there will be risks in the distant future. If we choose this risky policy, the standard of living will be somewhat higher over the next century. We do choose this policy. As a result, there is a catastrophe many centuries later. Because of geological changes to the Earth's surface, an earthquake releases radiation, which kills thousands of people. Though they are killed by this catastrophe, these people will have had lives that are worth living. We can assume that this radiation affects only people who are born after its release, and that it gives them an incurable disease that will kill them at about the age of 40 . This disease has no effects before it kills (Parfit, 1984:371-2).

Woodard, developing the intuitive idea that those killed in further future are wronged by the adoption of the risky policy, argues that it

"seems plausible that the [people who are later killed by the leaking toxic waste], like other innocent people, have rights that others should not knowingly pursue policies that will kill, injure, or poison them or will create substantial risks of these results, at least when there is no 
weighty justification for such policies and alternative policies which involve no such risks are available" (Woodward, 1986:812).

Woodward's proposal, Boonin argues, cannot succeed, as the right in question is either too strong or too weak. Read simply as a right not to be killed, it is too strong (Boonin, 2014:118). Highways, for example, are designed according to safety standards that reduce, but do not eliminate, the risks associated with using them. Those risks are expected to eventuate in the death of certain number of drivers each year. Their deaths are correctly understood to be a consequence of past decisions about highway safety standards. But it is implausible to hold their right not to be killed to have been violated. Similarly, people are killed all the time as the result of past planning or design decisions that create unforeseeable risks that eventuate in freak accidents. No right not to be killed of those who end up dead is violated if the risk whose eventuation kills them was not reasonably foreseeable at the time it was created. Reading the right as a right to not be unjustifiably killed, on other hand, makes the right in question too weak. The adoption of the risky policy results in future deaths, but if the right is a right not to be unjustifiably killed, it will not speak to whether or not those deaths count as wrongful rights violations. They do only if adopting the risky policy was not justified. Settling that question is not a matter to which the right not to be unjustifiably killed can contribute.

We can make better sense of what Woodward is getting at, however, if we think of the right in question not as an entitlement of future people that a state of affairs not obtain in which they have been unjustifiably killed, but as a right that policy choices be made that give their vital interests appropriate weight in determining what risks of harm (or in some cases, virtually certain harms) they can be justifiably exposed to. So understood, those killed in the further future are not wronged because they have been killed (or when they are killed). What wrongs them, rather, is that at the time of deciding between the policy alternatives, a decision was made to gamble with their lives, for no compelling reason, by adopting a policy that created a non-trivial risk that what does in fact happen will happen. That they are killed alters the significance of that wrong in their lives, and in standard cases, would have implications for how we think about their claim to compensation. It does not bear on whether they are in fact wronged by the adoption of the risky policy.

Finally, to return to the question of how to think about the morality of Wilma's choice, the proposed way of thinking about rights-claims lacks the implausible implication that Wilma wrongs Pebbles by conceiving her, 
even if she is only able to conceive children who will be born blind. Pebbles' right is not to a state of affairs obtaining in which she exists as sighted rather than in a 'harmed state' as blind. Rather, what her right entitles her to is Wilma giving appropriate weight, in her deliberations about when to conceive, to the interests of her future child in not being born blind. If that cannot be affected by when Wilma decides to conceive, Pebbles' right cannot be violated by that choice.

\section{RIGHTS-BASED SOLUTIONS AND WIDE-PERSON- AFFECTING PRINCIPLES}

The understanding of rights advanced in the last section-as claims individuals have against others that they regulate their conduct in a way consistent with the protection of one another's vital interests-is one I think of as being distinctively non-consequentialist in character. The proposal is that it takes us some way towards redeeming the promise of appealing to rights in non-identity cases.

It only goes some of the way because it appears to falter over the matter of the identity of the right holder. Recalling the distinction between direct and indirect versions of a rights-based approach, the way of appealing to rights in non-identity cases I am proposing is direct. It says that Wilma violates Pebbles' right when she chooses to conceive Pebbles rather than Rocks; an indirect argument would locate the objection to conceiving Pebbles in bringing into existence a person who will exist with an important right of hers violated. The indirect approach was rejected because, in positing a right not to be born in a certain state, it misconstrues the interpersonal role of rights. In particular, it leaves out a crucial dimension of rights as demands individuals make of another that they constrain their conduct in ways that embody recognition of one another's vital interests. A direct approach captures that aspect of rights, but it appears to problematically posit as a right-holder a person who does not, and will not, exist unless the very choice is made that respect for her right requires not be made. That is a deeply puzzling idea.

One way to think about the problem, prompted by the earlier discussion of rights, that makes it less puzzling goes as follows: what Wilma's child's right to be born sighted rather than blind amounts to is a requirement that she give a special weight, in her deliberations concerning whether and when to conceive, to the interests of the future child, choosing the course that looks to be reasonably protective of the child's interests. The 'interests of the child' in question are not, however, the interests of any particular 
child, but those of a generically described child (or the interests' children typically have).

Boonin considers a suggestion along these lines under the heading of the 'actual and de dicto' people approach. It holds that Wilma choosing to bring Pebbles into existence wrongs Pebbles because doing so is unfair. We can see why it is unfair if we think about what principle governing fair procreative choice would be chosen from an impartial point of view, described by a veil of ignorance. The veil secures the impartiality of the choice made behind it by depriving all those concerned-a domain that includes Wilma, Pebbles, and Rocks - of any information relevant to determining the particular people they are. The question to be considered is what principle for the regulation of procreative choice is it rationale for them to adopt in light of its implications for both a woman and her child, understanding 'her child' in a de dicto rather than a de re sense. As Boonin explains,

"the claim that Wilma wants to marry the tallest man in Bedrock, for example, could mean two different things: that there is a particular man that Wilma wants to marry who happens to be the tallest man in Bedrock (the de re reading) or that she wants to marry whatever man turns out to satisfy the description "the tallest man in Bedrock" (the de dicto reading)" (Boonin, 2014:31).

In asking what principle it would be rational to choose behind the veil, then, are the implications of different possible principles regulating procreative choice given the equal likelihood of turning out to be (a) a woman with a slight preference for conceiving a blind child now rather than sighted child in a few months' time, (b) the child she conceives, who could either be blind or sighted, or (c) someone for whom the principle has no implications. Reasoning this way supports the conclusion that the principle it is rational to accept is one that requires that Wilma delay conception because the worse-case scenario for the worst off person is not as bad as the worse-case scenario that imposes no such obligation (Boonin, 2014:135).

Boonin concludes that this line of argument does not succeed. Why that is so rests on a point that is evident when we compare the use of the veil of ignorance device in this case with how it is used by John Rawls and John Harsanyi, in the context of reasoning about principles for fair distribution. The veil they describe asks us to imagine a range of social positions, each of which describes someone's social circumstances. Reasoning behind the veil, what a person has to ask herself is how she would choose to have the 
goods of cooperation distributed across the social positions, knowing that one of them characterizes not just some actual person's life, but her life.

The veil of ignorance being appealed to in defense of Wilma's obligation to delay conceiving is different, insofar as it asks us to consider the implications of the principle for different lives that may or not turn out to be actual, depending on what choice is made, rather than the lives that, outside the veil, are the lives of actual people. Taking into account, behind the veil, the implication of a principle for merely possible lives is unmotivated. It is easy to understand the motivation for including behind it the implications of a principle for the lives people will in fact be leading outside of it. The concern is to be able to arrive at a principle that will allow the circumstances of their lives to be justified to them as fair. But nothing analogous can be said in favor of taking into account merely possible lives. The best reason for doing so, that it allows us to avoid biting the nonidentity bullet, is obviously question begging (Boonin, 2014:136).

There is, however, another way of thinking about what the de dicto appeal to the interests of Wilma's child is getting at that avoids the implausible appeal to the interests of 'possible people'. What derails the idea of appealing to the interests of the child de dicto is treating being born blind rather than sighted as an identity-fixing fact, such that Wilma's choice between her child between born blind or sighted is a choice between two possible lives, only one of which will be actual. The alternative reading says that the way to understand Wilma's choice is as a choice between her child being blind or sighted, where the life we are referring to is a life that will be actual, that of her child, whichever choice she makes (Boonin, 2014:138).

This reading succeeds, Boonin argues, only if we assume that whether a person is blind or sighted is not identity fixing. Doing so allows us to think of Pebbles and Rocks as representing two possibilities for one and the same person. As he puts it, this reading

"produces the desired result....only because it views conceiving blind Pebbles rather than sighted Rocks as making the person who is conceived worse off than that very person would otherwise have been. This means that this version of the approach can justify the claim that Wilma's act is morally wrong only by treating the case as one that is not a non-identity case. But if the approach works only in cases that are not non-identity cases, then it cannot solve the non-identity problem" (Boonin, 2014:138).

It is, I agree, implausible to treat the choice between creating a blind or a 
sighted child as not affecting the identity of the child, such that we can say that it is worse for a particular child to have been born blind than sighted. But this is not a claim that a defender of the alternative reading of the de dicto argument needs to make. What she should instead say is that the objection to Wilma's choice, from an impartial point of view, makes no appeal to the comparative claim that choosing to conceive Pebbles rather than Rocks is worse for her child. She should, rather, defend the principle requiring Wilma to choose to conceive Rocks rather than Pebbles as what Parfit calls a wide-person affecting principle. Such a principle

"makes claims about the intrinsic goodness of different outcomes.... When we apply the Wide Principle, we can consider each outcome on its own, and ask how good or bad this outcome would be for people. An outcome's intrinsic goodness does not depend on its relation to other outcomes" (Parfit 2017:140). ${ }^{4}$

Narrow person-affecting principles, on the other hand, are not concerned with "intrinsic goodness or badness, [so] we cannot consider each outcome on its own. We cannot ask whether some outcome would be bet for people, or worse for people, since these relations are essentially comparative, holding only between different outcomes" (Parfit 2017:140).

Parfit characterizes wide and narrow person-affecting principles as applying to the assessment of outcomes. They can, however, be readily put to work in the context of thinking about the justification of rights by restating them in deontic rather than telic terms. So understood, they are principles that bear on the assessment of choices rather than outcomes. A narrow deontic principle makes claims about which choices are better or worse for people, while a wide deontic principle makes claims about the intrinsic goodness or badness of a choice for people.

The claim that 'Wilma's prospective child' has a right to Wilma choosing to conceive a sighted rather than a blind child is most plausibly understood in wide deontic person-affecting terms, eschewing any appeal to comparative claims about what is better or worse for the child. What the right entitles 'Wilma's child' (understood de dicto) to is that Wilma constrain her deliberations so as to make choices concerning her child that are, given the information available to her, defensible as consistent with a concern for what will be intrinsically good for her child. The right is therefore violated by Wilma making a choice that will foreseeably result in

4 Boonin is careful to distinguish the 'moderate principle' he ultimately endorses from the narrow person-affecting principle (Boonin, 2014:276). 
her child being born blind when there is an adequate alternative option available, not simply by it being born blind. It has no bite if Wilma is only able to conceive blind children.

I cannot here try and address all the objections to the line of argument I have been developing; I will just consider two. The first points out that the way of thinking about the wrong Wilma does to Pebbles I am proposing leaves us unable to square Wilma's deliberative perspective in making her choice with that of the particular child created. Say Wilma goes ahead and conceives Pebbles. The suggestion is that in doing so, she wrongs Pebbles by violating her right. Because she is wronged, her experiencing certain reactive attitudes, like resentment or blame, associated with having been wronged would be completely justified. But in this case, it is hard to see why Pebbles should resent, or blame Wilma. Wilma's choice, after all, had no bad implications for Pebbles, and that it did not is not just a matter of luck. Wilma's choice, that is, is in no way an affront to Pebbles.

The idea that a person's objection to conduct that wrongs her must be personal gains support from the intuitive association of having been wronged with reactive attitudes like blame and resentment. What nonidentity cases show us is that this association is potentially misleading, insofar as it leads us to conclude that the test for whether a person has been wronged is to ask ourselves what justifies the wronged personally complaining about the wrongdoer's conduct. Pebbles has no personal complaint to lodge against Wilma's choice because that choice could not express an attitude towards her in particular; at time of the choice, she was only available to Wilma in her deliberations under the description of 'my future child'.

What follows, however, is not that she cannot claim to have been wronged, but that the basis of her complaint is in an important respect less personal. Wilma's choice wrongs her child because it is not in conformity with her obligation, having decided to have a child, to make choices that reasonably prioritizes the protection of the child's interests. Pebbles can feel indignation towards Wilma for choosing not to wait two months before conceiving. And she can resent that choice when she thinks of herself under the more impersonal description of 'Wilma's child'. It is in virtue of it uniquely applying to her that she can identify herself as the person wronged by Wilma's choice. In another, more personal, respect, however, she cannot, as long as she has a particular life to which she is attached, resent Wilma making the choice she did. Which is not to say that Pebbles' waives her right that Wilma not make the choice she did; because the right is one that constrains Wilma's choices with respect to 'her future child', it is not a right that any particular future child who ends up coming into 
existence is in a position to waive.

The second objection protests that locating the grounds of Pebbles' claim to be wronged in a more impersonal consideration lacks a rationale apart from that of wanting to evade the non-identity problem. A plausible attempt to solve the non-identity problem cannot employ the problem's evasion as part of the argument in support of it. ${ }^{5}$

The rationale for the move in question does not in fact appeal to the non-identity problem. What it relies on is a general feature of rights-claims, as I understand them. If you have a right against me that I not make a certain choice, this is in virtue of the character of the relation we stand in to one another, not in considerations having to do with us as particular individuals. To illustrate, consider the right to privacy. Bob has a right that Sue not read his e-mail without his permission. That is because the relation between them is one of strangers. Now, Bob does not in fact mind if strangers read his e-mail without seeking his consent (there is nothing in it he would not happily reveal if asked). He would even welcome someone doing so because it would be evidence of someone taking a special interest in his life. But that has no bearing on his right that Sue not read his email without his consent. That right is one he has against Sue in virtue of the fact that they are strangers to one another; the right to privacy is one that governs relations between strangers, protecting interests that those who are strangers to one another typically have. Sue may come to know, through a third party, that Bob would welcome a stranger breaking into his e-mail account and reading his messages. But that would not change the salient, comparatively impersonal, fact that their being strangers to one another is sufficient grounds for her reading his e-mail without his consent to constitute, and for her to conclude that her doing so would, wronging Bob by violating his right to privacy.

\section{CONCLUSION}

In this brief discussion, I have argued that the prospects for a rights-based solution to the non-identity problem remain good, despite Boonin's forceful arguments to the contrary. In arguing for this position, I have appealed to various aspects of non-consequentialist thinking about rights and their moral significance that I believe any successful rights-based solution to the non-identity problem needs to emphasize. Whether such a strategy can ultimately be vindicated can only be settled by further exploration of what the best version of such a solution looks like.

5 Boonin calls this the 'independence requirement' (Boonin, 2014:20). 


\section{BIBLIOGRAPHY}

Boonin, D.,2014: The Non-Identity Problem and the Ethics of Future People, Oxford: Oxford University Press

Oberdiek, J.,2004: "Lost in moral space: On the infringing/violating distinction and its place in the theory of rights", Law and Philosophy 23: 325-346.

Parfit, D., 1984: Reasons and Persons, Oxford: Oxford University Press

-2017: "Future People, the Non-Identity Problem, and Person-Affecting Principles" Philosophy and Public Affairs 45 2:118-57.

Woodard, J., 1986: “The Non-Identity Problem” Ethics Vol. 96 4:804-831. 